\title{
A ELABORAÇÃO DE PLANOS DIRETORES EM CIDADES PEQUENAS: REFLEXÕES SOBRE OS LIMITES E PERSPECTIVAS AO DESENVOLVIMENTO LOCAL
}

\author{
Luciane Maranha de Oliveira Marisco \\ Universidade Federal de Alagoas, Instituto de Geografia, Desenvolvimento e Meio Ambiente, \\ Maceió, AL, Brasil \\ luciane.marisco@igdema.ufal.br
}

\begin{abstract}
RESUMO - Este artigo apresenta alguns resultados da elaboração dos Planos Diretores dos municípios de Campestre, Flexeiras, Jacuípe e Jundiá no estado de Alagoas, apontando para a reflexão do papel do planejamento urbano nas políticas públicas de desenvolvimento local. A metodologia de elaboração destes Planos Diretores teve como pressuposto teórico/metodológico o que dispõe o Estatuto da Cidade (2001) e o Guia "Plano Diretor Participativo: guia para elaboração pelos municípios e cidadãos do Ministério das Cidades" (2004). Os resultados geraram um diagnóstico destes municípios, e subsidiou a elaboração de diretrizes de desenvolvimento local e de planejamento urbano a curto, médio e longo prazo. Contudo, revelou também as dificuldades que se colocam a implantação de um processo de planejamento urbano em municípios de pequeno porte, com elevados índices de pobreza urbana e estagnação econômica.
\end{abstract}

Palavras-Chave: Planejamento urbano; Desenvolvimento urbano; Gestão urbana.

\section{THE ELABORATION OF DIRECTOR PLANS IN SMALL TOWNS: REFLECTIONS ON LOCAL DEVELOPMENT LIMITS AND PROSPECTS}

\begin{abstract}
This article presents some results of the preparation of Master Plans of the municipalities of Campestre, Flexeiras, Jacuípe and Jundiá in the state of Alagoas, pointing to the reflection of the role of urban planning in public policies for local development. A method for preparing these Master Plans had theoretical / methodological assumption which provides the City Statute (2001) and the Guide "Participative Master Plan: guide to preparing for municipalities and citizens of the Ministry of Cities" (2004). The results led to a diagnosis of these municipalities, and supported the development of guidelines for local development and urban planning in the short, medium and long term. However, it also revealed the difficulties facing the implementation of a process of urban planning in small municipalities with high levels of urban poverty and economic stagnation.
\end{abstract}

Keywords: Urban planning; Urban development; Urban management.

\section{INTRODUÇÃO}

Entender as lógicas que regem a dinâmicas urbanas locais necessita um esforço de análise que implica, por sua vez, entender as lógicas capitalistas que regem as dinâmicas socioeconômicas em escalas geográficas mais amplas (da global a nacional), com reflexos no espaço geográfico nas mais diferentes escalas. No caso aqui analisado apresentamos algumas reflexões sobre a inserção dos municípios de Flexeiras, Jacuípe, Jundiá e Campestre em Alagoas no atendimento aos interesses capitalistas mais amplos, que extrapolam a escala local e as dinâmicas que regem estas localidades. Estes municípios situam-se geograficamente na área de influência direta de implantação do gasoduto Pilar/Ipojuca na região nordeste do Brasil, sob responsabilidade da Transportadora Associada de Gás/Petrobras, sendo que estas obras visam ampliar e reforçar a malha de gasodutos da região Nordeste do Brasil, juntamente com o Gasene (Gasoduto Sudeste-Nordeste), e que se enquadra em um projeto mais amplo da Petrobras de expansão da malha de gasodutos no Brasil, denominado Programa Ampliação 
Malha de Dutos do Nordeste, o que Milton Santos denomina de promoção da fluidez do território para o capital. A elaboração dos Planos Diretores destes municípios insere-se, portanto, em um contexto mais amplo que o da escala local e teve como objetivos geral e específico, a necessidade destes municípios contemplarem o que prevê a Constituição Federal (artigos 182 e 183) e o Estatuto da Cidade-Lei Federal 10.257/01 (artigo 41), tendo em vista que estes municípios se enquadram na situação prevista no artigo 41 do Estatuto da Cidade, segundo o qual o Plano Diretor é obrigatório para cidades "inseridas na área de influência de empreendimentos ou atividades com impacto ambiental de âmbito regional ou nacional", e enquadram-se também nos termos do $\$ 1^{\circ}$ do artigo 41, "no caso da realização de empreendimentos ou atividades de significativo impacto de âmbito regional ou nacional, os recursos técnicos e financeiros para a elaboração do Plano Diretor estarão inseridos entre as medidas de compensação adotadas." Desse modo a Petrobras promoveu uma licitação para a sua elaboração, sendo a Universidade Federal de Alagoas através da Faculdade de Arquitetura e Urbanismo-FAU, a responsável pelo gerenciamento deste processo, com a estruturação de um grupo de trabalho multidisciplinar para subsidiar estes municípios na elaboração de seus Planos Diretores Participativos, que ocorreu no período de 2009-2010.

A Leitura Técnica Preliminar da cidade e do território municipal foi construída com base no levantamento e sistematização de informações acerca da realidade dos municípios, nos temas relativos aos indicadores socioeconômicos, uso e ocupação do solo urbano e rural, meio ambiente e saneamento ambiental, infraestrutura e serviços públicoinstitucionais, realizadas pelos profissionais da UFAL/FAU (alunos e professores de diversos cursos de graduação), com as equipes técnicas das Prefeituras locais, e com a participação da sociedade através das Audiências Públicas. O documento final (Plano Diretor) constitui hoje o mais completo diagnóstico que estes municípios possuem sobre as realidades e necessidades locais, servindo de subsídio a gestão e as políticas públicas urbanas. É um instrumento que se colocado em prática, irá contribuir no enfrentamento dos problemas das mais diversas ordens que afetam estes municípios (econômica, social, política), e que se expressam nas mais diversas formas: como a exclusão social, urbanística e territorial de sua população, a pobreza urbana e a estagnação econômica.

\section{REDE URBANA DA REGIÃO NORDESTE E DO ESTADO DE ALAGOAS}

A rede urbana de Alagoas integrante da rede urbana da região nordeste apresenta características singulares da formação territorial, histórica e socioeconômica desta região. Diversos são os estudos que explicam as características desta rede de cidades (MOTA e AJARA,2001; MAIA, 2010; SANTOS, 1993; CORRÊA, 1989, CORRÊA, 1992, LUBAMBO et al., 2005). Para (LUBAMBO et al.,2005) a rede urbana na região nordeste configura-se por uma hierarquia diferenciada, marcada pela centralização das regiões metropolitanas, e ainda em decorrência dos fluxos de investimentos produtivos e de populações nas últimas décadas "aexistência e convivência de vários nordestes" (p.354). Uma das características marcantes é o expressivo número de cidades pequenas: na faixa de 1.000 a 5.000 habitantes com um total de 716 cidades, de 5.001 a 20.000 habitantes com um total de 748 cidades, seguida em menor número das faixas de 20.001 a 50.000 habitantes, com 156 cidades; 50.001 a 100.000 habitantes com 38 cidades; de 100.001 a 500.000 habitantes com 31 cidades; e com mais de 500.000 habitantes somente 09 cidades, sendo que 08 são capitais de estado. (MAIA, 2010, pg. 26-34). A tabela 1 ilustra estes dados. 
Tabela 1 - Rede Urbana Nordestina por faixa populacional

\begin{tabular}{|c|c|c|c|c|c|c|}
\hline $\begin{array}{c}\text { Cidades } \\
\text { com até } \\
1.000 \\
\text { habitantes }\end{array}$ & $\begin{array}{c}\text { Cidades de } \\
1.000 \mathrm{a} \\
5.000 \\
\text { habitantes }\end{array}$ & $\begin{array}{c}\text { Cidades } \\
\text { entre } \\
5.001 \mathrm{e} \\
20.000 \\
\text { habitantes }\end{array}$ & $\begin{array}{c}\text { Cidades } \\
\text { entre } \\
20.001 \mathrm{e} \\
50.000 \\
\text { habitantes }\end{array}$ & $\begin{array}{l}\text { Cidades } \\
\text { entre } \\
50.001 \mathrm{e} \\
100.000 \\
\text { habitantes }\end{array}$ & $\begin{array}{c}\text { Cidades } \\
\text { entre } \\
100.001 \mathrm{e} \\
500.000 \\
\text { habitantes }\end{array}$ & $\begin{array}{c}\text { Acima de } \\
500.000 \\
\text { habitante }\end{array}$ \\
\hline 88 & 716 & 748 & 156 & 38 & 31 & 9 \\
\hline
\end{tabular}

Fonte: MAIA (2010)

Com base nesta classificação MAIA assinala sobre a rede urbana do Nordeste:

\begin{abstract}
Destarte as particularidades econômicas pontuais, percebe-se uma similaridade entre as denominadas cidades pequenas do Nordeste, em especial a forte relação campocidade, que se revela na economia municipal, em que a agricultura e a pecuária aparecem como os principais componentes econômicos, assim como a incipiente oferta de serviços e ainda um comércio bastante restrito, especialmente naquelas de menor contingente populacional. Nas cidades acima de 50 mil habitantes, tanto os serviços como o comércio são mais diversificados, sendo reveladores da centralidade desses núcleos. (...) Vale acrescentar que parte da economia dos municípios cujas sedes apresentam contingente populacional inferior a 20 mil habitantes provém da gestão da economia rural ou de recursos da União. (MAIA,2010,p.29)
\end{abstract}

Considerando as especificidades e singularidades das redes de cidades na região nordeste em função de aspectos históricos, culturais, políticos, econômicos e sociais inerentes às dinâmicas de cada estado, a rede urbana do estado de Alagoas expressa as mesmas características da região nordeste. Dos 102 municípios que compõem a rede urbana, a sua maioria são de cidades pequenas na faixa de 5.001 a 20.000 habitantes, totalizando 57 cidades, seguida da faixa de 20.001 a 50.000 habitantes com 30 cidades. Na faixa de 1.000 a 5.000 habitantes são apenas 06 cidades; na faixa entre 50.001 a 100.000 habitantes são 07 cidades; 01 cidade média e de porte médio (Arapiraca) com 214.006 habitantes e 01 cidade grande (Maceió), capital do estado com 932.748 habitantes (IBGE-Censo Demográfico 2010). A Tabela 2 ilustra estes dados.

Tabela 2 - Rede Urbana de Alagoas por faixa populacional

\begin{tabular}{|c|c|c|c|c|c|}
\hline $\begin{array}{c}\text { Cidades de } \\
1.000 \\
\text { a } 5.000 \\
\text { habitantes }\end{array}$ & $\begin{array}{c}\text { Cidades entre } \\
5.001 \\
\text { e } 20.000 \\
\text { habitantes }\end{array}$ & $\begin{array}{c}\text { Cidades entre } \\
20.001 \text { e } 50.000 \\
\text { habitantes }\end{array}$ & $\begin{array}{c}\text { Cidades entre } \\
50.001 \mathrm{e} \\
100.000 \\
\text { habitantes }\end{array}$ & $\begin{array}{c}\text { Cidades entre } \\
100.001 \mathrm{e} \\
500.000 \\
\text { habitantes }\end{array}$ & $\begin{array}{c}\text { Acima de } \\
500.000 \\
\text { habitantes }\end{array}$ \\
\hline 6 & 57 & 30 & 7 & 1 & 1 \\
\hline
\end{tabular}

Fonte: IBGE (Censo Demográfico 2010)

Nesta pesquisa constatou-se que estes municípios mantém uma forte relação com a área rural, evidenciado pelos dados da População Economicamente Ativa (IBGE, 2000) em que a maior parte de sua população está empregada no setor primário da economia, seguida em menor proporção pelo setor terciário, com destaque para o poder público (Prefeituras Municipais) o maior empregador. Outra característica marcante é a grande dependência econômica destes municípios das transferências federais através dos diversos programas como: Bolsa Família, Fundeb, Fundo de Participação dos Municípios e a Previdência Social. A afirmação de (CARVALHO,2008) ilustra esta realidade, "A previdência social, principalmente a rural, mais as transferências federais ajudam a explicar como se mantêm as pequenas localidades do interior alagoano." (pg.81). CORRÊA em artigo que apresenta um estudo sobre a constituição da rede urbana de Alagoas já chamava atenção para estas características e que se mantém ainda hoje: 
(...) A este fraco índice de urbanização, característico das regiões de economia predominantemente agrícola, se junta um fato que diminui mais ainda esse índice: a presença de pessoas exercendo atividades agrárias, porém residindo em cidades. Este fato ocorre numa escala apreciável nas pequenas cidades da área canavieira. (...) Por outro lado muitas dessas sedes municipais (32 das 69) não alcançam sequer 2.000 habitantes. Uma segunda característica do fato urbano alagoano diz respeito à grande amplitude demográfica entre Maceió (150.000 habitantes) e as demais cidades do estado, pois, destas a maior, não chega a apresentar 20.000 habitantes. (CORRÊA, 1992, pg. 93)

Tratando sobre as características desta rede urbana CORREAA revela o papel que tiveram os meios de transportes na formação desta rede e a divide em três grandes fases:

\begin{abstract}
a primeira fase que se estende de meados do século XVI até o início da penúltima década do século XIX em que o transporte fluvial foi determinante na formação de muitas cidades; a segunda fase que se estende do fim do século XIX até a Segunda Guerra Mundial denominado pelo autor de as cidades "ponta de trilhos" devido o impacto espacial que teve o advento da ferrovia na constituição da rede urbana; e a terceira fase que tem início após a Segunda Guerra Mundial, no início do século XX denominada de "nós rodoviários", com a introdução de um novo meio de transporte, o rodoviário, acarretando profundas alterações, reforçando a posição hierárquica de alguns centros e reduzindo de outros. Expressas pela importância das velhas cidades litorâneas, velhas não só no tempo, mas na organização de seu espaço e nas suas funções, das cidades "ponta de trilhos" e "nós rodoviários" as três fases da vida urbana de Alagoas estão marcadas na paisagem de cada uma delas. Os velhos sobradões, as igrejas barrocas, coexistem ao lado de cidades cuja arquitetura está ligada ao fim do século passado e início deste e, também,ao lado daquelas onde os postos de gasolina, as oficinas mecânicas e os hotéis sempre cheios, marcam uma nova fase na vida urbana. Estes contrastes da fisionomia urbana de diversos centros ressaltam, em grande parte, da verdadeira revolução ocorrida no sistema de transportes. (CORRÊA, 1992, p.116)
\end{abstract}

A dinâmica destas pequenas cidades e sua inserção na rede urbana regional e estadual reflete, por sua vez, sua constituição histórica evidenciando as raízes da dependência econômica e social. Estes municípios se inserem na Mesorregião do Leste Alagoano, sendo que Jundiá, Campestre e Jacuípe estão situados no extremo norte do Estado de Alagoas, na divisa com o Estado de Pernambuco, e Flexeiras está localizado no nordeste do estado. Embora Flexeiras não integre a região Metropolitana de Maceió, pertence ao pólo de influência da capital, apenas $59 \mathrm{~km}$. (Figura 1)

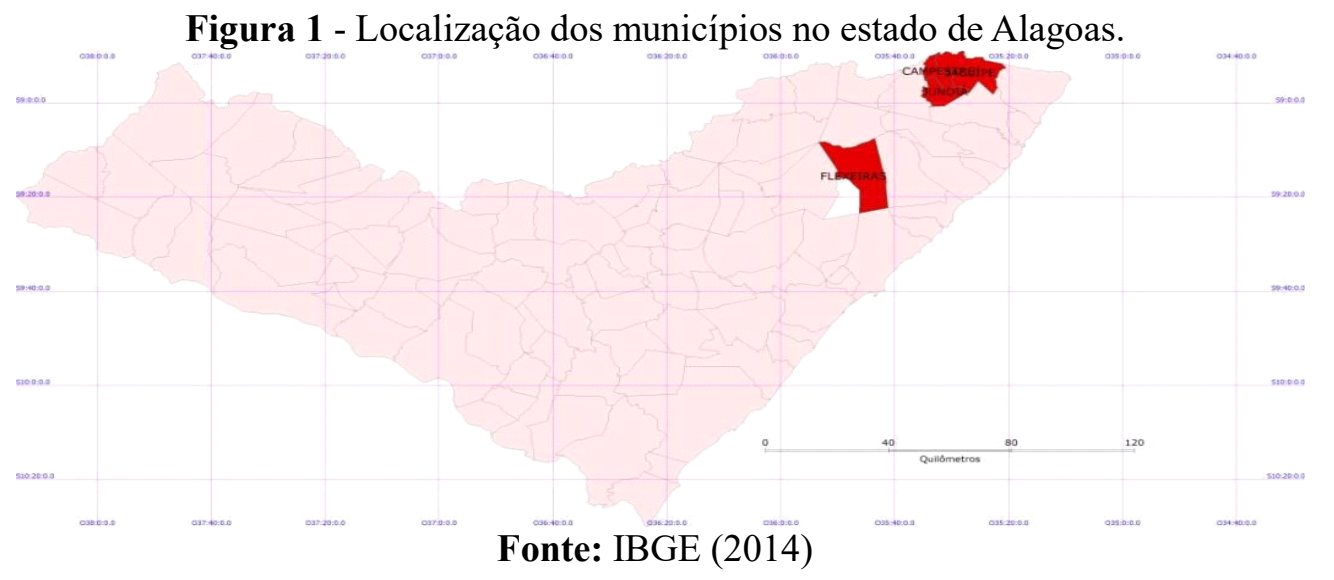

A formação do núcleo de povoamento de Flexeiras teve início ainda no século XIX, quando seu território pertencia a Porto de Pedras/AL, devido à região bastante fértil, nela teria sido instalado um engenho de açúcar. Por sua vez, Campestre, Jacuípe e Jundiá possuem suas raízes históricas inseridas na dinâmica da colonização do território conquistado pelos europeus, e aos indígenas seus primeiros habitantes. 
De acordo com (Lindoso,2005), foi em torno de Porto Calvo que primeiro se estruturou uma sociedade de modelo patriarcal, formada pelos senhores de engenho brancos e pela mão-de-obra escrava, inicialmente os índios capturados e, posteriormente, o negro trazido da África para trabalhar nas grandes propriedades canavieiras. Estas práticas estabeleceram os fundamentos econômicos, políticos e sociais do território das Alagoas e que refletem até hoje em sua estruturação socioespacial (Plano Diretor Participativo, 2010). As heranças deste modelo ainda são visíveis na paisagem, na cultura local e na economia calcada no latifúndio e na monocultura da cana-de-açúcar para exportação.

Os municípios supracitados, portanto, refletem essa herança, pois a economia local centrada na produção canavieira ainda é a principal fonte de renda e empregos local. Ressalta-se que os diagnósticos revelaram aspectos importantes para uma análise da contextualização destes municípios no estado, e as possibilidades de inserção nas políticas de desenvolvimento estadual e local. Identificou as deficiências, as potencialidades e as demandas locais, assim como, permitiu traçar diretrizes de desenvolvimento socioeconômico e territorial que tenham relação com as realidades encontradas.

Devido à abrangência deste diagnóstico privilegia-se neste artigo a amostragem de alguns indicadores sociais, econômicos e de gestão pública, que revelam as potencialidades e as deficiências locais. Se por um lado, as potencialidades poderão constituir os caminhos para o desenvolvimento, por sua vez, as deficiências são entraves para a superação dos diversos problemas que se manifestam na sociedade e no espaço geográfico, como por exemplo, a pobreza, os elevados índices de analfabetismo e desemprego, e a dependência econômica da monocultura canavieira e dos repasses federais.

\section{PERFIL SOCIOECONÔMICO E APONTAMENTOS SOBRE AS DEFICIENCIAS E POTENCIALIDADES.}

As informações apresentadas a seguir correspondem a Leitura Técnica participativa da cidade e do território municipal, através das pesquisas documentais, Oficinas Comunitárias, Capacitações e Audiências Públicas. Objetiva-se apresentar sucintamente algumas deficiências e potencialidades balizadoras das reflexões propostas para este artigo. Os indicadores demográficos revelam características comuns, são cidades pequenas que enquadram-se na faixa de 5.001 a 20.000 habitantes, com exceção de Jundiá com 4.202 habitantes. Embora, a maior parte da população esteja concentrada na zona urbana, a dinâmica econômica local é dada pela economia rural através da monocultura da cana-deaçúcar.

O Censo Demográfico de 2010 indica Flexeiras com 12.325 habitantes, Jacuípe 6.997 habitantes, Campestre 6.598 habitantes e Jundiá com 4.202 habitantes. A produção realizada pelos pequenos produtores rurais (mandioca, feijão, milho, laranja, banana, maracujá, batatadoce, abacaxi, coco da baia, pimenta do reino, etc.,), constitui uma das potencialidades destas localidades. As Figuras 2 e 3 ilustram algumas destas potencialidades econômicas. 
Figura 2 - Plantação de inhame -Fazenda Boa Vista (Jacuípe)

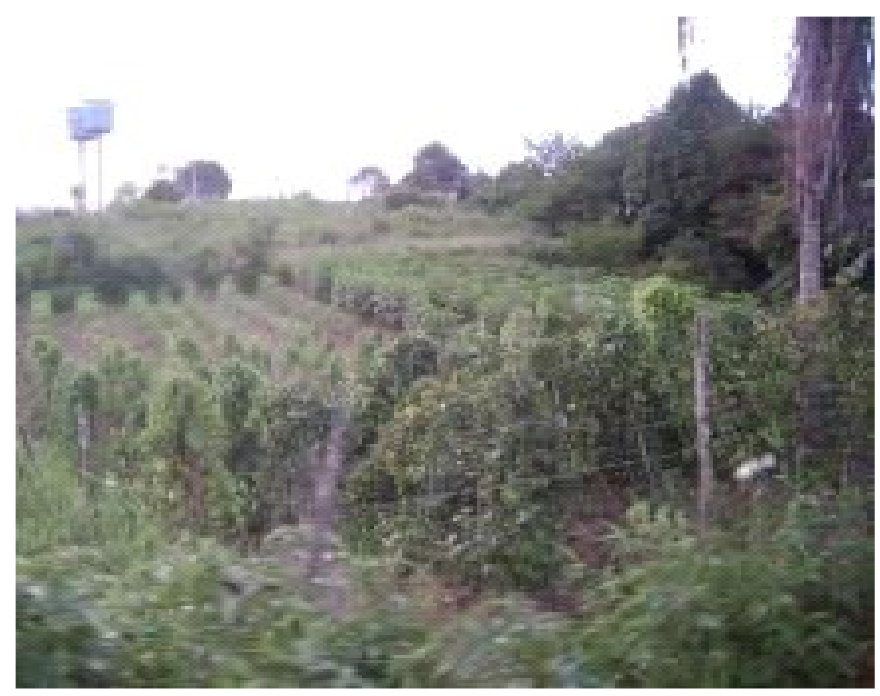

Fonte: Banco de Imagens PDP/Junho 2009

Figura 3: Casa de Farinha, Sítio Serrinha (Campestre).

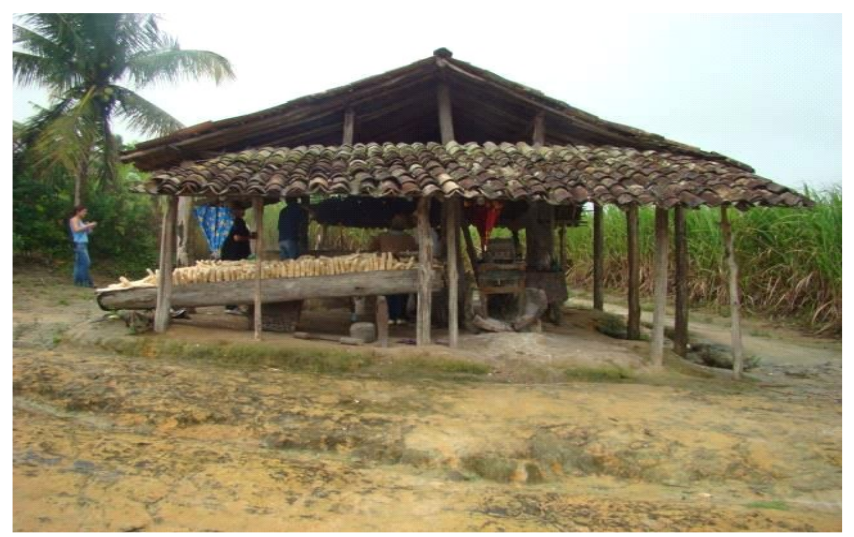

Fonte: Banco de Imagens PDP/Junho 2009.

As consequências de uma difusão seletiva das modernizações no território brasileiro, a herança histórica de uma estrutura fundiária com base no latifúndio e de uma economia baseada no modelo agroexportador da cana-de-açúcar, podem ser analisadas através de alguns indicadores como Renda e Índice de Desenvolvimento Humano-IDH.

Soma-se aos fatores acima, o pouco dinamismo do setor da indústria, do comércio e dos serviços que se reflete nas economias locais através de uma economia pouco dinâmica e que explica em parte a forte dependência da população das rendas provenientes das transferências governamentais do estado e do Governo Federal.

As rendas provenientes de transferências governamentais correspondem às aposentadorias, pensões e programas oficiais de auxílio tais como: Renda Mínima, Bolsa-Escola, SeguroDesemprego, Aposentadorias, etc. A pobreza, as altas taxas de analfabetismo, os baixos índices de saúde em que está inserida a população não permite uma melhoria na qualidade de vida em todas as suas esferas. Os índices de renda para todos os municípios para o período 1991 e 2000 foram os que menos tiveram evolução. A Tabela 3 apresenta esses índices com base nos dados do Atlas de Desenvolvimento Humano (PNUD,2003). 
Tabela 3 - Índice de Desenvolvimento Humano entre os anos de 1991 e 2000

\begin{tabular}{|c|c|c|c|c|c|}
\hline Municípios & Anos & $\begin{array}{c}\text { IDH } \\
\text { Educação }\end{array}$ & $\begin{array}{c}\text { IDH } \\
\text { Longevidade }\end{array}$ & $\begin{array}{c}\text { IDH } \\
\text { Renda }\end{array}$ & $\begin{array}{c}\text { IDH } \\
\text { Municipal }\end{array}$ \\
\hline Flexeiras & 1991 & 0,398 & 0,490 & 0,432 & 0,440 \\
\hline & 2000 & 0,587 & 0,608 & 0,468 & 0,554 \\
\hline Jacuípe & 1991 & 0,305 & 0,582 & 0,452 & 0,446 \\
\hline & 2000 & 0,559 & 0,634 & 0,450 & 0,548 \\
\hline Jundiá & 1991 & 0,434 & 0,500 & 0,472 & 0,469 \\
\hline & 2000 & 0,587 & 0,631 & 0,461 & 0,560 \\
\hline Campestre & 1991 & 0,478 & 0,517 & 0,450 & 0,482 \\
\hline & 2000 & 0,657 & 0,601 & 0,489 & 0,582 \\
\hline
\end{tabular}

Fonte: Programa das Nações Unidas para o Desenvolvimento PNUD- Atlas de Desenvolvimento Humano no Brasil (2003).

Outro dado que revela o baixo poder aquisitivo da população é o da População Economicamente Ativa (PEA) com rendimento. Os dados do IBGE (2000) revelam uma similaridade entre os municípios pesquisados quanto a esse indicador. A maior parte da população recebe um rendimento na faixa de "mais de $1 / 2$ a 1 salário mínimo", seguida das faixas que recebem "mais de 1 a 2 salários mínimos", e aqueles que recebem "mais de 1/4 a 1/2 salário mínimo". (Salário Mínimo no valor de $\mathrm{R} \$ 465,00$, referente ao ano base de 2004).

Em Jacuípe o número total de pessoas ocupadas com rendimento corresponde a 1.529, sendo que a grande maioria (873 pessoas) recebe na faixa de "mais de $1 / 2$ a 1 salário mínimo, e 380 pessoas recebem na faixa de "mais de 1 a 2 salários mínimos". Em Campestre do total de 1.482 pessoas com rendimento, (658 pessoas) recebem na faixa de "mais de 1/2 a 1 salário mínimo", seguida de 351 pessoas na faixa de "mais de 1 a 2 salários mínimos". Em Jundiá para o total de 1.191 pessoas com rendimento, (580 pessoas) recebem na faixa de "mais $1 / 2$ a 1 salário mínimo" e 349 pessoas na faixa de "mais de 1 a 2 salários mínimos", em Flexeiras, do total da população ocupada com rendimento (3.069 pessoas) 1.637 pessoas recebem na faixa de "mais de $1 / 2$ a 1 salário mínimo, e 908 pessoas recebem na faixa de "mais de 1 a 2 salários mínimos".

Outra característica comum entre esses municípios é o setor primário da economia como o principal setor de empregabilidade, com a maior parte da população empregada na agricultura, seguida do setor terciário, com ênfase na administração pública (Prefeituras Municipais), seguida do comércio e dos serviços. As Tabelas 4, 5, 6 e 7 apresentam a composição da renda da população por município e por tipo de repasses. Nota-se para todos os municípios no período analisado, que houve um aumento da renda proveniente de repasses do Governo Federal e uma diminuição da renda proveniente do trabalho, o que reforça a constatação sobre a forte dependência das cidades e da população dos repasses do Governo Federal. 
Tabela 4 - Composição da renda da população de Flexeiras

\begin{tabular}{|l|l|l|}
\hline \multicolumn{1}{|c|}{ Composição da renda por tipo de repasse } & 1991 & 2000 \\
\hline$\%$ da renda proveniente de transferências governamentais & 11,25 & 14,99 \\
\hline$\%$ da renda proveniente de rendimentos do trabalho & 87,69 & 67,19 \\
\hline$\%$ de pessoas com mais de 50\% da renda provenientes de transferências governamentais & 7,40 & 14,14 \\
\hline
\end{tabular}

Fonte: Programa das Nações Unidas para o Desenvolvimento - PNUD

Atlas de Desenvolvimento Humano no Brasil (2003)

Tabela 5 - Composição da renda da população de Campestre

\begin{tabular}{|l|l|l|}
\hline \multicolumn{1}{|c|}{ Composição da renda por tipo de repasse } & 1991 & 2000 \\
\hline$\%$ da renda proveniente de transferências governamentais & $11,37 \%$ & $21,88 \%$ \\
\hline$\%$ da renda proveniente de rendimentos do trabalho & $82,37 \%$ & $57,60 \%$ \\
\hline$\%$ de pessoas com mais de $50 \%$ da renda provenientes de transferências governamentais & $6,92 \%$ & $21,06 \%$ \\
\hline
\end{tabular}

Fonte: Programa das Nações Unidas para o Desenvolvimento - PNUD

Atlas de Desenvolvimento Humano no Brasil (2003)

Tabela 6 - Composição da renda da população de Jacuípe

\begin{tabular}{|c|c|c|}
\hline Composição da renda por tipo de repasse & 1991 & 2000 \\
\hline$\%$ da renda proveniente de transferências governamentais & $9,77 \%$ & $18,52 \%$ \\
\hline$\%$ de pessoas com mais de $50 \%$ da renda provenientes de transferências governamentais & $7,84 \%$ & $17,37 \%$ \\
\hline
\end{tabular}

Fonte: Programa das Nações Unidas para o Desenvolvimento - PNUD

Atlas de Desenvolvimento Humano no Brasil (2003)

Tabela 7 - Composição da renda da população de Jundiá

\begin{tabular}{|c|c|c|}
\hline Composição da renda por tipo de repasse & 1991 & 2000 \\
\hline \% da renda proveniente de transferências governamentais & $7,80 \%$ & $18,49 \%$ \\
\hline$\%$ da renda proveniente de rendimentos do trabalho & $85,12 \%$ & $56,73 \%$ \\
\hline$\%$ de pessoas com mais de $50 \%$ da renda provenientes de transferências governamentais & $5,64 \%$ & $17,97 \%$ \\
\hline
\end{tabular}

Fonte: Programa das Nações Unidas para o Desenvolvimento - PNUD

Atlas de Desenvolvimento Humano no Brasil (2003) 
Quanto aos índices de educação destacam-se as altas taxas de analfabetismo em todos os municípios, sendo que mais da metade da população é analfabeta. Campestre com 49,48\%, Flexeiras com 55,37\%, Jundiá com 56,15\% e Jacuípe com 58,58\%. Para os indicadores de saúde é interessante notar que embora os dados de fontes oficiais informem que as principais causas da mortalidade estão relacionadas a doenças do aparelho circulatório, respiratório e neoplasias, as informações obtidas através de pesquisa direta nos postos de saúde e durante as Oficinas Participativas e Capacitações com as populações locais, foi apontado como maiores causas de mortalidade aquelas relacionadas a qualidade da água distribuída e consumida na cidade, ou seja, a deficiência dos serviços de infraestrutura urbana (saneamento básico) ofertado a população, sendo uma das principais causas de mortalidade, principalmente a infantil, a esquistossomose.

Demais deficiências identificadas para o conjunto dos municípios foram: o êxodo rural, as más condições de trabalho na cultura canavieira, as dificuldade de venda dos produtos agrícolas pelos pequenos produtores rurais nas feiras locais, a estagnação econômica, a migração periódica, a inexistência de cooperativas agrícolas, a pobreza urbana, a ausência de políticas públicas geradoras de renda, a sazonalidade dos empregos nas lavouras, o fechamento de destilarias, fábricas e casas de farinha gerando desemprego local. O modelo econômico secular, centrado na monocultura canavieira com base no latifúndio e que perdura até hoje, é uma das causas centrais para se entender os índices de pobreza e o pouco dinamismo econômico local. Em todos os municípios a estrutura fundiária é o latifúndio. Embora no município de Jacuípe existam dois expressivos assentamentos rurais (Canafístula e Boa Vista), com grande número de pessoas vivendo da agricultura familiar, e em Campestre e Jundiá existam um número expressivo de pequenas propriedades rurais com agricultura de subsistência, com o cultivo da macaxeira, batata, inhame, milho, banana entre outros produtos, constatou-se que não tem sido um fator determinante para a mudança da economia local no sentido de imprimir um maior dinamismo e desenvolvimento econômico. A gestão pública também foi objeto de análise, e tendo em vista o papel determinante do planejamento nas políticas de desenvolvimento urbano sabe aqui algumas considerações. A gestão urbana não perpassa somente a esfera técnica e administrativa, mas também, e, sobretudo, a esfera política e a esfera legal.

A estrutura institucional da gestão pública reflete o modo de fazer política local, e as deficiências listadas a seguir refletem o que se afirmou acima: ausência de Cadastro Territorial Urbano ou outro tipo de Cadastro Municipal, ausência de Conselho de Política Urbana e outros Conselhos para subsidiar as políticas públicas locais, estrutura organizacional das prefeituras deficitária (inadequação dos espaços físicos, recursos humanos pouco qualificados, estrutura operacional deficitária em todos os municípios), poucas Leis municipais no âmbito urbanoambiental e outras Leis que tratam da política de gestão urbana, a necessidade de atualização da legislação existente, a falta de parcerias institucionais em vários setores (educação, saúde, emprego e renda, ação social, etc.). O subitem a seguir apresenta as potencialidades que se constituem em meios para a superação dos entraves ao desenvolvimento destes municípios.

\section{AS POTENCIALIDADES COMO UMA VIA PARA O DESENVOLVIMENTO URBANO LOCAL.}

As informações obtidas de dados oficiais e fontes diretas resultaram, nos diagnósticos setoriais e permitiu traçar o perfil socioeconômico dos municípios e sua inserção espacial em relação às políticas públicas de desenvolvimento local e estadual. Devido a amplitude dos dados coletados (Economia, Saúde, Educação, Ação Social, Esporte, Cultura, Recreação e Lazer, Segurança Pública, Gestão Pública e Institucional, Infra-Estrutura, Condicionantes Ambientais, Uso e Ocupação do Solo Urbano e Rural), iremos nos deter nas potencialidades e diretrizes no campo dos aspectos socioeconômicos e institucionais que remete as discussões deste artigo. 
Se por um lado estas pequenas cidades apresentam um conjunto significativo de deficiências, por outro lado, comportam um conjunto de potencialidades que poderão ser balizadoras da indução de um crescimento e desenvolvimento destes núcleos urbanos a médio e longo prazo, rompendo com a dependência econômica centrada em políticas econômicas altamente concentradoras de riqueza para uma elite local/estadual e de pobreza para a maior parte das populações residentes. As potencialidades locais foram identificadas por temas comuns a todos os municípios. Em virtude da extensão destas temáticas não se fará neste artigo uma análise de cada uma, mas apontar-se-ão as características gerais e que serviram de subsídios as diretrizes definidas nos Planos Diretores elaborados.

A presença da agricultura familiar como alternativa de emprego e renda, as Casas de Farinha e as Feiras Livres como instâncias dinamizadoras do comércio e distribuição das mercadorias produzidas pela agricultura familiar, a presença das pequenas propriedades rurais, a cultura da cana-de-açúcar como geradora de emprego e renda. É interessante notar o destaque que a população que participou das Audiências Públicas deu a este tema, o que reforça o papel da cultura canavieira nas economias destes pequenos municípios empregando a grande parcela da população e sua enorme dependência.

Outros temas relacionam-se as especificidades da economia e dos aspectos socioculturais de cada município como: as potencialidades turísticas (turismo ecológico, turismo cultural), a melhoria na qualidade e variedade dos produtos agrícolas produzidos localmente, a pecuária de pequeno porte, os projetos para o desenvolvimento e ampliação da piscicultura, etc.. As diretrizes de desenvolvimento socioeconômico e urbanístico apontadas no Plano Diretor representa uma via alternativa na superação do modelo econômico imposto: concentrador e ao mesmo tempo excludente. Concentrador de renda e de benefícios a uma pequena parcela da população, as elites econômicas e políticas (locais, estaduais e regionais), que há séculos comandam a economia no estado. E excludente, pois esse modelo não incorpora a maior parte da população dos benefícios gerados por esse modelo.

É listado a seguir um conjunto de diretrizes socioeconômicas e institucionais, que se forem incorporadas como prioridades nas políticas públicas urbanas, em âmbito municipal, e em articulação com a esfera estadual, contribuirão para uma maior autonomia econômica e financeira promovendo o dinamismo destas localidades:

- Estabelecimento de uma política de incentivo a produção em pequena escala com base na agricultura familiar e na piscicultura;

- Incentivo a agroindústria a partir do beneficiamento de frutas (doces caseiros) e da mandioca (Farinha e fécula), através da formação de Associações visando à instalação de Cooperativas;

- Incentivo e apoio a organização dos pequenos produtores agrícolas;

- Busca de parcerias para a implementação de um Programa de Concessão de Financiamento e Assistência Técnica para os pequenos produtores rurais, que inclua também a população de assentados;

- Desenvolvimento de uma política local para a exploração do turismo ecológico e do patrimônio histórico-cultural de forma a se constituir como fonte alternativa de emprego e renda;

- Criação de uma Cooperativa para os pequenos produtores rurais;

- Desenvolvimento de projetos e programas voltados à fixação do homem no campo;

- Fortalecimento da produção de mandioca e o seu beneficiamento, com a criação de cooperativa de produtores de farinha;

- Elaboração de projeto para a construção de uma fábrica de rapadura e derivados da cana-deaçúcar;

- Desenvolvimento de programas e projetos voltados ao desenvolvimento social e econômico 
dos municípios;

- Elaboração de política de incentivo fiscal para a atração de indústria para os municípios;

- Suporte para a capacitação de produtores rurais e criação de uma cooperativa e/ou associação para a produção agrícola dos assentados e apoio ao escoamento da produção local;

- Elaboração do Cadastro Municipal para a prefeitura subsidiar as ações no âmbito da política de desenvolvimento urbano;

- Instituir parcerias interinstitucionais para apoio ao desenvolvimento de programas e ou projetos nas diversas áreas (educação, saúde, ação social, etc.);

- Constituir o Conselho da Cidade (ou de Desenvolvimento Urbano) como instância consultiva e deliberativa nas questões relacionadas ao desenvolvimento urbano, e definir instâncias de participação da população na gestão da cidade;

- Melhorar/adequar a estrutura administrativa e operacional para qualificação da gestão pública, de forma a adequar o sistema de gestão, possibilitando o monitoramento, o controle e a fiscalização das ações, conforme o que for estabelecido no Plano Diretor;

- Atualizar as leis já existentes no âmbito urbano-ambiental e criar novos instrumentos legais necessários.

Tais propostas somente terão possibilidade de serem colocadas em prática através da parceria entre os poderes públicos, municipal e estadual. São diretrizes que remetem a elaboração de políticas públicas urbanas a médio e longo prazo. A elaboração dos Planos Diretores Participativos foi o primeiro passo neste processo de planejamento e gestão pública. Os diagnósticos revelaram a realidade desses municípios e respectiva inserção socioeconômica no estado. As diretrizes são, por enquanto, propostas, que para viabilizá-las será necessário um esforço conjunto das respectivas esferas de poder. Será necessário assumir novas posturas para que se coloque em prática políticas e programas que possam, definitivamente, romper com o ciclo vicioso de eterna dependência desses municípios e sua população.

A tarefa de planejar contempla um conjunto de condicionantes que lhe conferem os limites e as possibilidades, visto que promover a organização do espaço urbano e o desenvolvimento não existe por si mesmo, mas faz parte de um conjunto de fatores externos, que fornecerão a sua exequibilidade ou não. Estes fatores externos relacionam-se aos aspectos políticos (de composição de forças políticas), os aspectos econômicos e sociais (de grupos hegemônicos), técnicos, que se referem às condições técnicas para que ocorra a implantação de um processo de planejamento, relacionado aos recursos humanos, financeiros, de estrutura administrativa do poder público local, pois o processo de planejamento não se implanta somente em função da elaboração do Plano Diretor, mas de todas as condições acima referidas.

Para que este se constitua em um processo contínuo e permanente, no qual os instrumentos de regulação urbanística são um dos seus produtos, faz-se necessário incorporar a "cultura do planejamento" na gestão pública, sendo assimilado como um método de ação, que possui uma dimensão técnica e, sobretudo, uma dimensão política. Tendo em vista a dinâmica do urbano e o papel dos diversos agentes que produzem as cidades, o papel do planejamento urbano é criar e garantir através dos instrumentos urbanísticos, que o desenvolvimento e a produção do espaço urbano se dê com base na socialização das riquezas geradas e rompa com a lógica de sua privatização.

\section{AGRADECIMENTOS}

Agradecemos o apoio financeiro da Petrobras/Transportadora Associada de Gás S. A. (TAG 
S.A) através da abertura de licitação pública ganha pela Faculdade de Arquitetura e Urbanismo-FAU no período 2009-2010 para o Projeto de Extensão intitulado "Elaboração dos Planos Diretores Participativos dos Municípios Alagoanos de Campestre, Flexeiras, Jacuípe e Jundiá", em que a Universidade Federal de Alagoas, o Curso de Arquitetura e Urbanismo, a FUNDEPES e PETROBRAS/TAG S.A, estabeleceram parceria. Os resultados ora apresentados é fruto desta parceria que possibilitou bolsas de fomento aos docentes e discentes envolvidos de diversas áreas de conhecimento (Cursos de Arquitetura e Urbanismo, Geografia, Serviço Social e Direito). Agradecemos a todos os profissionais envolvidos (docentes, discentes e técnicos) pela realização deste trabalho.

\section{REFERÊNCIAS}

BRASIL, Ministério das Cidades. Plano Diretor Participativo: Guia para Elaboração pelos Municípios e Cidadãos. Brasília: MCidades, 2004.

BRASIL, Estatuto da Cidade: Lei $\mathbf{n}^{0}$ 10.257, 10 de julho de 2001, que estabelece diretrizes gerais da política urbana. Brasília: Câmara dos Deputados, Coordenações de Publicações, 2001.

CARVALHO, Cícero Péricles de. Economia popular: uma via de modernização para Alagoas. Maceió: Edufal, 2008.

CORRÊA, Roberto Lobato. A Rede urbana. São Paulo: Ática, 1989. (Série Princípios nº.168)

CORRÊA, Roberto Lobato. A vida urbana em Alagoas: a importância dos meios de transportes na sua evolução. Revista Terra Livre, Espaço \& Memória, AGB, 10 jan-jul, São Paulo, 1992. pg. 93-116.

FUNDAÇÃO UNIVERSITÁRIA DE DESENVOLVIMENTO DE EXTENSÃO E PESQUISA/UNIVERSIDADE FEDERAL DE ALAGOAS - FUNDEPES/UFAL. Plano Diretor Participativo dos Municípios de Flexeiras, Campestre, Jacuípe, Jundiá e Messias. Relatórios 2, 3 e 4 Parcial - Parte I e II - Pré-Diagnóstico dos Municípios: Sensibilização, Capacitação e Leitura Técnica Preliminar, Consolidação das Contribuições das Oficinas Comunitárias, 2009. MARISCO, Luciane M. de O. (Coord.). Maceió, 2009/2010.

LINDOSO, Dirceu. Formação de Alagoas Boreal. Maceió: Edições Catavento, 2000.

MAIA, Doralice Sátyro. Cidades médias e pequenas do nordeste: Conferência de Abertura. In: Cidades médias e pequenas: teorias, conceitos e estudos de caso. Diva Maria Ferlin Lopes, Wendel Henrique (Org.). Salvador: SEI, 2010. pg.15-41

MOTTA, Diana Meirelles da e AJARA, Cesar. Configuração da Rede Urbana do Brasil.

Revista Paranaense Desenvolvimento. Curitiba, n. 100, jan/jun, 2001. pg. 7-25.

SANTOS, Milton. A urbanização brasileira. São Paulo: Hucitec, 1993.

INSTITUTO BRASILEIRO DE GEOGRAFIA E ESTATÍSTICA-IBGE. Censo Demográfico 2000. Disponível em: <http://www.ibge.gov.br/home/estatistica/populacao/censo2000/default.shtm>. Acesso em: 10 Janeiro de 2010.

INSTITUTO BRASILEIRO DE GEOGRAFIA E ESTATÍSTICA - IBGE. Contagem da População $2007 . \quad$ Disponível em: $<$ http://www.ibge.gov.br/home/estatistica/populacao/contagem2007/contagem final/tabela1_1_14.pdf $>$ . Acesso em: 10 Janeiro de 2010.

LUBAMBO, Cátia et al. Urbanização Recente na Região Nordeste: dinâmica e perfil da rede urbana, 2005. Disponível em: Disponível em: <www.fundaj.gov.br>. Acesso em: 20 de junho 2013.

PROGRAMA DAS NAÇÕES UNIDAS PARA O DESENVOLVIMENTO - PNUD. Atlas do Desenvolvimento Humano no Brasil. Cálculo do Índice de Desenvolvimento Humano Municipal (IDHM). 2003. Disponível em: $<$ http://www.pnud.org.br/atlas/textos_analiticos/index.php>. 